\title{
Diminutive Gastrointestinal Lesions in Cholesterol Crystal Embolization
}
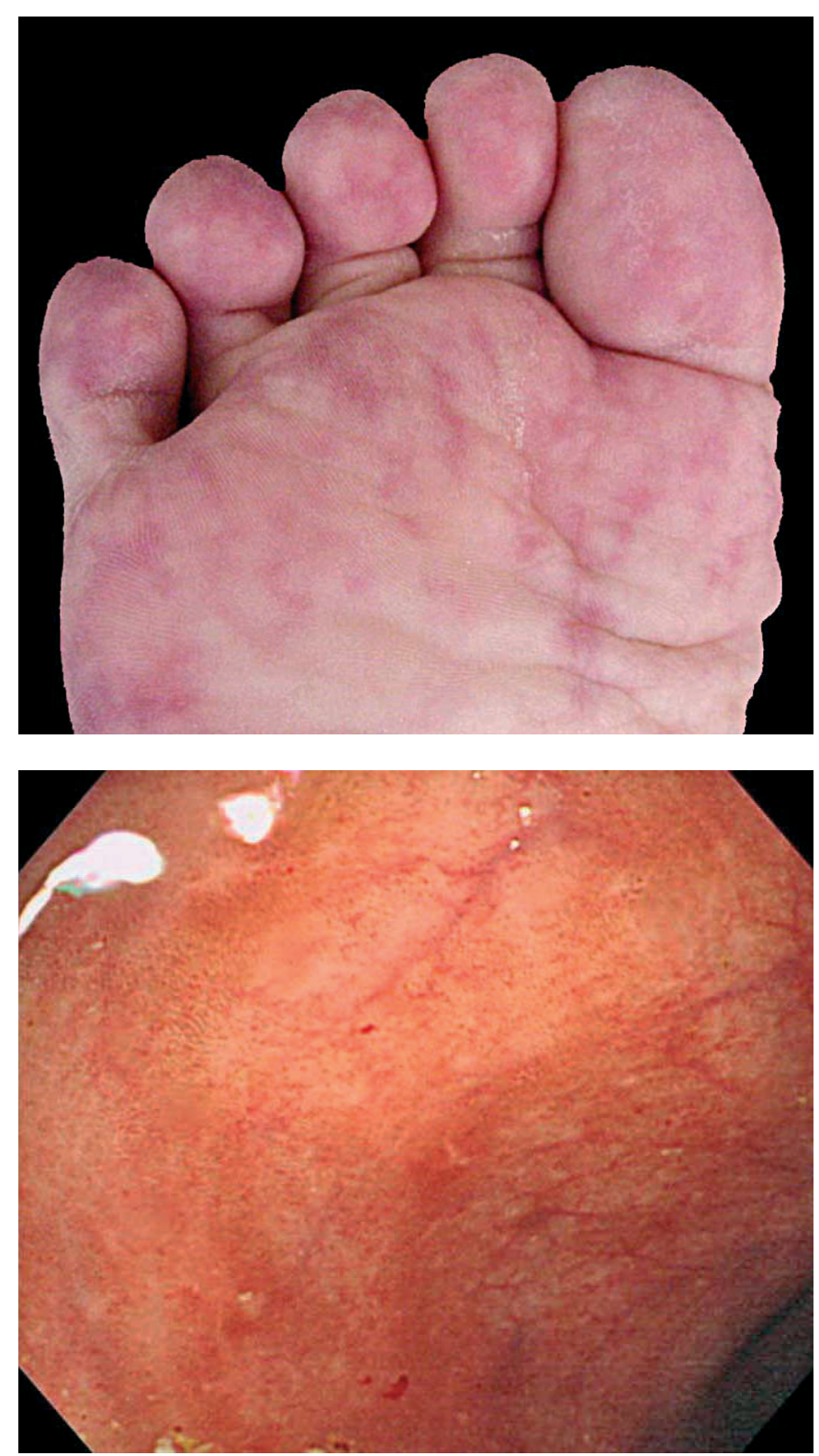

Figure 3 Colonoscopy showed aphthoid lesions in the rectum. Our experience suggests that diminutive gastrointestinal lesions may be frequent in patients with CCE.
Figure 1 Cholesterol crystal embolization (CCE) is a condition characterized by systemic embolization of cholesterol crystals from atherosclerotic plaques lining in the walls of major arteries. We found diminutive gastrointestinal lesions in four of five patients with CCE. Here, livedo reticularis is seen in the foot of a 70-year-old man with CCE. A biopsy specimen from the livedo reticularis contained a cholesterol cleft in an arteliole of the upper dermis.
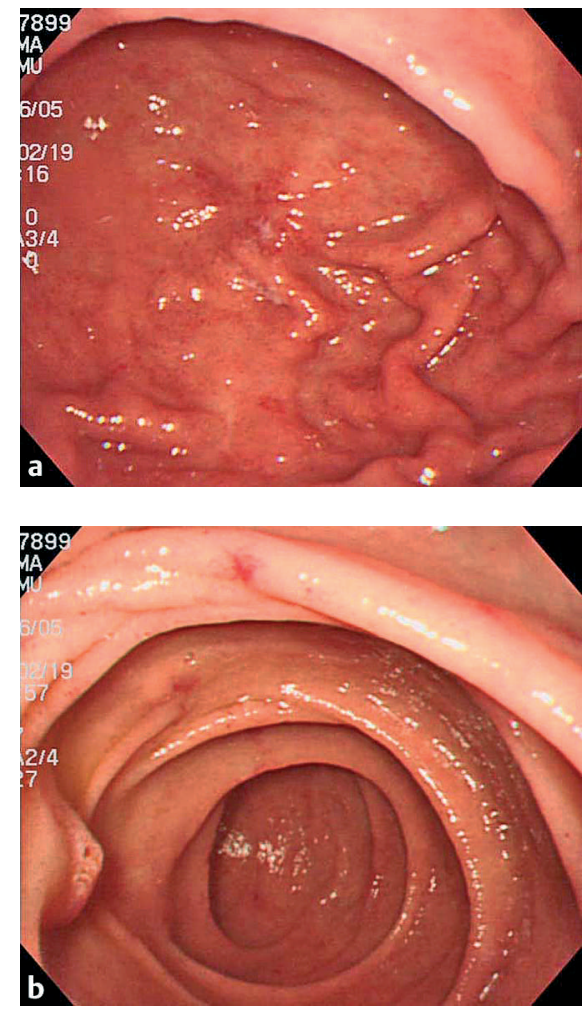

Figure 2 Gastroduodenoscopy of the patient showed: a diffuse erythemas and erosions in the gastric body; and $\mathbf{b}$ scattered mucosal redness in the second portion of the duodenum.

M. Hirahashi 1,2, T. Matsumoto 1, M. Esaki ${ }^{1}$, M. Nagata ${ }^{1}$, H. Hirakata ${ }^{1}$, T. Yao ${ }^{2}$, M. Iida ${ }^{1}$

${ }^{1}$ Department of Medicine and Clinical Science, Graduate School of Medical Sciences, Kyushu University, Fukuoka, Japan

2 Department of Anatomic Pathology, Graduate School of Medical Sciences, Kyushu University, Fukuoka, Japan

\section{Corresponding Author}

\section{Hirahashi, M.D.}

Department of Medicine and Clinical Science, Graduate School of Medical Sciences, Kyushu University

Maedashi 3-1-1

Higashi-ku Fukuoka 812-8582

Japan

Fax: $\quad+81-92-6425273$

E-mail: mi-hira@surgpath.med. kyushu-u.ac.jp 